NASA/TM-2004-212481

\title{
Underexpanded Screeching Jets From Circular, Rectangular, and Elliptic Nozzles
}

J. Panda

Modern Technologies Corporation, Middleburg Heights, Ohio

G. Raman

NYMA, Inc., Brook Park, Ohio

K.B.M.Q. Zaman

Glenn Research Center, Cleveland, Ohio 
Since its founding, NASA has been dedicated to the advancement of aeronautics and space science. The NASA Scientific and Technical Information (STI) Program Office plays a key part in helping NASA maintain this important role.

The NASA STI Program Office is operated by Langley Research Center, the Lead Center for NASA's scientific and technical information. The NASA STI Program Office provides access to the NASA STI Database, the largest collection of aeronautical and space science STI in the world. The Program Office is also NASA's institutional mechanism for disseminating the results of its research and development activities. These results are published by NASA in the NASA STI Report Series, which includes the following report types:

- $\quad$ TECHNICAL PUBLICATION. Reports of completed research or a major significant phase of research that present the results of NASA programs and include extensive data or theoretical analysis. Includes compilations of significant scientific and technical data and information deemed to be of continuing reference value. NASA's counterpart of peerreviewed formal professional papers but has less stringent limitations on manuscript length and extent of graphic presentations.

- TECHNICAL MEMORANDUM. Scientific and technical findings that are preliminary or of specialized interest, e.g., quick release reports, working papers, and bibliographies that contain minimal annotation. Does not contain extensive analysis.

- CONTRACTOR REPORT. Scientific and technical findings by NASA-sponsored contractors and grantees.
- CONFERENCE PUBLICATION. Collected papers from scientific and technical conferences, symposia, seminars, or other meetings sponsored or cosponsored by NASA.

- SPECIAL PUBLICATION. Scientific, technical, or historical information from NASA programs, projects, and missions, often concerned with subjects having substantial public interest.

- TECHNICAL TRANSLATION. Englishlanguage translations of foreign scientific and technical material pertinent to NASA's mission.

Specialized services that complement the STI Program Office's diverse offerings include creating custom thesauri, building customized databases, organizing and publishing research results ... even providing videos.

For more information about the NASA STI Program Office, see the following:

- Access the NASA STI Program Home Page at http://www.sti.nasa.gov

- E-mail your question via the Internet to help@sti.nasa.gov

- Fax your question to the NASA Access Help Desk at 301-621-0134

- Telephone the NASA Access Help Desk at 301-621-0390

- Write to:

NASA Access Help Desk

NASA Center for AeroSpace Information 7121 Standard Drive

Hanover, MD 21076 
NASA/TM-2004-212481

AIAA-97-1623

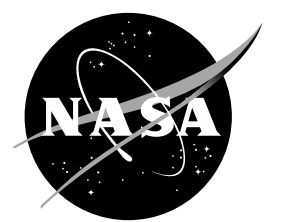

\section{Underexpanded Screeching Jets From Circular, Rectangular, and Elliptic Nozzles}

J. Panda

Modern Technologies Corporation, Middleburg Heights, Ohio

G. Raman

NYMA, Inc., Brook Park, Ohio

K.B.M.Q. Zaman

Glenn Research Center, Cleveland, Ohio

Prepared for the

Third Aeroacoustics Conference

cosponsored by the American Institute of Aeronautics and Astronautics and the Confederation of European Aerospace Societies

Atlanta, Georgia, May 12-14, 1997

National Aeronautics and

Space Administration

Glenn Research Center 


\section{Acknowledgments}

The authors acknowledge Mr. James R. Stone of Modern Technologies Corporation for reviewing this paper.

J. Panda would like to acknowledge some helpful discussion with Dr. Alan B. Cain of the McDonnell Douglas Corporation.

This report has been prepared by using provided electronic files.

Note that at the time of research, the NASA Lewis Research Center was undergoing a name change to the

NASA John H. Glenn Research Center at Lewis Field.

Both names may appear in this report.

Available from

NASA Center for Aerospace Information 7121 Standard Drive

Hanover, MD 21076
National Technical Information Service 5285 Port Royal Road Springfield, VA 22100 


\title{
UNDEREXPANDED SCREECHING JETS FROM CIRCULAR, RECTANGULAR AND ELLIPTIC NOZZLES
}

\author{
J. Panda \\ Modern Technologies Corporation \\ Middleburg Heights, Ohio 44130 \\ G. Raman \\ NYMA, Inc. \\ Brook Park, Ohio 44142 \\ K.B.M.Q. Zaman \\ National Aeronautics and Space Administration \\ Glenn Research Center \\ Cleveland, Ohio 44135
}

\begin{abstract}
The screech frequency and amplitude, the shock spacing, the hydrodynamic-acoustic standing wave spacing, and the convective velocity of large organized structures are measured in the nominal Mach number range of $1.1 \leq \mathrm{M}_{\mathrm{j}} \leq 1.9$ for supersonic, underexpanded jets exhausting from a circular, a rectangular and an elliptic nozzle. This provides a carefully measured data set useful in comparing the importance of various physical parameters in the screech generation process. The hydrodynamic-acoustic standing wave is formed between the potential pressure field of large turbulent structures and the acoustic pressure field of the screech sound. It has been demonstrated earlier (Panda, AIAA 96-1718) that in the currently available screech frequency prediction models replacement of the shock spacing by the standing wave spacing provides an exact expression. In view of this newly found evidence a comparison is made between the average standing wavelength and the average shock spacing. It is found that there exists a small, yet important, difference, which is dependent on the azimuthal screech mode. For example, in the flapping modes of circular, rectangular and elliptic jets, the standing wavelength is slightly longer than the shock spacing, while for the helical screech mode in a circular jet the opposite is true. This difference accounts for the departure of the existing models from predicting the exact screech frequency.

Another important parameter, necessary in screech prediction, is the convective velocity of the large organized structures. It is demonstrated that the presence of the hydrodynamic-acoustic standing wave, even inside the jet shear layer, becomes a significant source of error in the convective velocity data obtained using the conventional methods. However, a new relationship, using the standing wavelength and screech frequency is shown to provide more accurate results.
\end{abstract}

\section{INTRODUCTION}

\section{A. Motivation}

Screech noise is produced by imperfectly expanded supersonic jets containing a quasi-periodic shock structure. It is of importance in military aircraft where very high dynamic loads associated with the screech tone are capable of causing tail plane structural failure (Hay and Rose ${ }^{1}$ ). An experimental program has been undertaken at NASA Lewis Research Center to address some of the unanswered questions associated with the screech prediction. The goal is to provide a database, and advance fundamental understanding, which can be used along with computational methods (Cain et. $\left.a l^{2}\right)$ to predict the frequency and amplitude of the screech tone.

In two earlier publications, Panda, ${ }^{3,4}$, some extremely detailed measurements of the shock structure, nearfield pressure fluctuation and the coherent turbulent structure's properties in the shear layer have been presented. The data provide a fresh, new look at the screech generation mechanism. A puzzling observation in ref 4, whose reason has remained unexplained, is that the length scale, which appears to govern the screech production mechanism, is somewhat different from the average shock spacing (L). This length scale is equal to the wavelength of a standing wave $\left(\mathrm{L}_{\mathrm{sw}}\right)$ formed between the potential pressure field of organized turbulent vortices in the jet shear layer and the pressure fluctuation from the sound waves. The former propagates downstream with the flow and the latter upstream against the flow. Traditionally shock spacing is used to provide for an approximate expression of the screech frequency (Powell ${ }^{5,6}, \mathrm{Tam}^{7}$, Morris $e t a l^{8}$.). It is demonstrated in ref 4 that an exact expression for the screech frequency is obtained by replacing the shock spacing with the standing wavelength. Moreover, the large organized structures, 
present inside the shear layer, are found to be periodically modulated at the standing wavelength spacing rather than the shock spacing. The above observations cast some doubts on the traditional explanation of the screech generation which relies on a periodic modulation of the organized coherent structures by the shock spacing. As a first step to solve this puzzle it is of interest to know the difference between the standing wave and shock spacing for jets issuing from nozzles of different contours and operating conditions. This has motivated the present work, where the above two length scales are compared for jets emitting from a circular, a rectangular and an elliptic nozzle in the fully expanded Mach number range of $1.1 \leq \mathrm{M}_{\mathrm{j}} \leq 1.9$.

An additional motivation for the present experimental investigation is to correctly measure the convective velocity of the large organized structures. This is a necessary parameter in all screech prediction models, and inaccuracy in its measurement is also suspected to contribute to the disagreement between the experimental and the predicted results. There are large discrepancies in the quoted values. This is illustrated in Table I where, previously published and the currently measured data are presented. All data are from unheated jets and the convective velocity, $U_{c}$, is normalized by the fully expanded jet velocity $U_{j}$. An examination of the previously published data from rectangular choked jet, in the nominal $\mathrm{M}_{\mathrm{j}}=1.4$, for example, shows an unacceptably large scatter from 0.44 to 0.7 . The possible cause for such a data scatter is discussed and a novel method of calculation using the standing wavelength data is presented.

\section{B. Hydrodynamic-acoustic standing wave}

Following is a brief discussion of the standing wave formation found in the vicinity of the shear layer. A detailed discussion can be found in ref 4 . It should be mentioned a priori that in the near field region of a screeching jet, there may be two types of standing wave patterns. The first one, which is of interest in the present paper, is between the downstream moving potential pressure field of organized vortices and the upstream propagating screech pressure fluctuations. The second one (not considered in the present paper) is due to the presence of sound reflectors, such as a flange or a reflector plate, that may reflect back the screech waves and produce a standing wave between the incident and reflected waves (Raman et al. ${ }^{15}$, Nagel et al. ${ }^{16}$ ). The first one is always present while the second one may or may not be present. The wavelength of the first type of standing wave can be calculated as follows:

In a screeching jet the acoustic and the hydrodynamic (potential pressure field) waves have the same frequency, $\omega$, different wavenumbers $\mathrm{k}_{\mathrm{s}}$ and $\mathrm{k}_{\mathrm{h}}$, and in general different amplitudes $\mathrm{A}$ and $\mathrm{B}$. The resultant fluctuation can be written as:

The mean square of which is:

$$
f=A \sin \left(k_{s} x+\omega t\right)+B \sin \left(k_{h} x-\omega t\right) .
$$

$$
\overline{\mathrm{f}}^{2}=\frac{\omega}{2 \pi} \int_{0}^{\frac{2 \pi}{\omega}} \mathrm{f}^{2} \mathrm{dt}=\frac{\mathrm{A}^{2}}{2}+\frac{\mathrm{B}^{2}}{2}-\mathrm{A} B \cos \left(\mathrm{k}_{\mathrm{s}}+\mathrm{kh}\right) \mathrm{x} .
$$

The above equation shows that a standing wave pattern is expected with a resultant wavenumber $k_{s w}=k_{s}+k_{h}$. Since, $\mathrm{k}_{\mathrm{h}}$ is associated with the hydrodynamic fluctuations of wavelength $\lambda_{\mathrm{h}}\left(\mathrm{k}_{\mathrm{h}}=2 \pi / \lambda_{\mathrm{h}}\right), \mathrm{k}_{\mathrm{s}}$ with the sound waves of wavelength $\lambda_{\mathrm{s}}\left(\mathrm{k}_{\mathrm{s}}=2 \pi / \lambda_{\mathrm{s}}\right)$, and $\mathrm{k}_{\mathrm{sw}}$ with the standing waves of wavelength $\mathrm{L}_{\mathrm{sw}}\left(\mathrm{k}_{\mathrm{sw}}=2 \pi / \mathrm{L}_{\mathrm{sw}}\right)$, the last variable satisfies the following:

$$
\frac{1}{\mathrm{~L}_{\mathrm{sw}}}=\frac{1}{\lambda_{\mathrm{s}}}+\frac{1}{\lambda_{\mathrm{h}}}
$$

It should be mentioned here that only a partial standing wave formation is expected, as the amplitudes A and B are unequal. It is straightforward to demonstrate that an exact expression for screech frequency formulae can be derived from the standing wave relationship. Since, $\lambda_{\mathrm{s}}=\mathrm{c} / \mathrm{f}_{\mathrm{s}}$, and $\lambda_{\mathrm{h}}=\mathrm{U}_{\mathrm{c}} / \mathrm{f}_{\mathrm{s}}$, (where $\mathrm{c}$ is the ambient sound speed, $\mathrm{f}_{\mathrm{s}}$ is the screech frequency, and $u_{c}$ is the average convective speed of hydrodynamic fluctuations) equation 2 can be written as:

$$
\frac{1}{\mathrm{~L}_{\mathrm{SW}}}=\frac{\mathrm{f}_{\mathrm{S}}}{\mathrm{c}}+\frac{\mathrm{f}_{\mathrm{S}}}{\mathrm{U}_{\mathrm{c}}} \text {. }
$$


Rearranging,

$$
\mathrm{f}_{\mathrm{s}}=\frac{\mathrm{U}_{\mathrm{c}}}{\mathrm{L}_{\mathrm{sw}}\left(1+\frac{\mathrm{U}_{\mathrm{c}}}{\mathrm{c}}\right)} .
$$

The only difference between the above exact expression and the modeling expressions of Powell ${ }^{6}$ and Fisher and Morfey ${ }^{17}$ is that the standing wavelength $\mathrm{L}_{\mathrm{sw}}$ replaces the average shock spacing $\mathrm{L}$. It is demonstrated in ref 4 that a similar difference exists between the above expression and the approximate model proposed by Tam et al. ${ }^{11} \mathrm{~A}$ common assumption in the existing screech models is that the distance between the individual point sources of sound is the average shock cell spacing. In view of equation 3 the correct distance should be the standing wavelength. A natural inquiry that follows is how much of a difference exists between the standing wavelength and the shock spacing. This is addressed in the section IIIB of this paper.

\section{EXPERIMENTAL SETUP}

The present experiments are conducted in free air jet facilities at the NASA Lewis Research Center. As mentioned in the title, three convergent nozzles of circular, rectangular and elliptic geometry have been used in this experiment. The axisymmetric, circular nozzle is of 25.4-mm diameter (D); the details of which can be found in ref 4. The 5:1 aspect ratio rectangular nozzle is the same one used earlier by Raman in ref 18; the smaller dimension (h) of the rectangle is $6.86 \mathrm{~mm}$. The major to the minor axis ratio of the elliptic nozzle is $3: 1$, with the major axis length of $25.4 \mathrm{~mm}$. This is the same nozzle used earlier by Zaman in ref 19. All of the nozzles were operated in underexpanded condition with supply to the ambient pressure ratios such that, if fully expanded, the Mach numbers $\left(\mathrm{M}_{\mathrm{j}}\right)$ would be in the range 1.1 to 1.9. This range, achieved by changing the supply pressure to the plenum chamber, represents operating conditions where screech is the strongest. The supply air was unheated with a total temperature of $294^{\circ} \mathrm{K}$. For unheated air flow from convergent nozzles screech either ceases to exist $\left(\operatorname{Raman}^{18}\right.$ ) or, becomes very weak beyond about $\mathrm{M}_{\mathrm{j}}=1.8$. The coordinate system adopted in this paper, expresses the downstream distance from the nozzle exit as $\mathrm{x}$, and the radial distance from the jet centerline as $r$. All data for the asymmetric nozzles are measured in the major axis (x-r) plane at the midspan.

The experimental data reported herein were obtained using non-intrusive techniques. The primary experimental tool, which has made the present investigation possible, is a laser based optical detection technique that depends on two types of light scattering phenomena. The first one is a strong scattering effect due to the shock waves, and appears when a narrow laser beam grazes a shock. The second one is two to three orders of magnitude weaker, and is associated with the refractive index fluctuations associated with the passing turbulent eddies. The fundamental optical property of a shock wave, which causes the first type of scattering, has been discussed by Panda ${ }^{20}$ and Panda \& Adamovsky $^{21}$. The shock detection technique based on this scattering phenomenon was discussed in ref 3. One of the methods to measure the convective speed of the organized turbulent structures was to use the second type of scattering, which is outlined more thoroughly in ref 4 . In either situation the optical method involves a narrow pencil of laser beam passing through the jet and normal to the flow direction. The scattered light, appearing within a narrow angle with respect to the beam propagation direction, is collected and measured by a photo-multiplier tube (PMT). The optical arrangement is shown in fig. 1. A green (0.514-mm wavelength) laser beam, separated from an Argon-ion laser and transmitted through a fiber optic system, is the central element. The $2 \mathrm{~mm}$-diameter laser beam coming out of the fiber-optic probe is focused to a $0.16 \mathrm{~mm}$ spot at the jet centerline and is allowed to cross the flow field. On the other side of the jet is a light collecting and measuring device, which senses the scattered light. There are a beam stop and an aperture stop just in front of the $60-\mathrm{mm}$ diameter collecting lens. The diameter of the beam stop is such that the main laser beam is blocked from entering the collecting optics while the scattered light can be easily collected. The collecting lens passes this light to a photomultiplier tube (PMT) via a pinhole. The electrical output from the PMT is amplified and connected across a $50 \mathrm{Ohm}$ terminator (not shown in fig. 1). The voltage drop across the terminator is an indicator of the intensity of the collected light.

The complete optical set-up (fiber-optic probe, beam stop and the collecting optics) was mounted on a traversing unit (Klinger) which allowed it to be positioned at various points along the jet shear layer. Under the no flow condition, light from the laser beam does not reach the PMT. However, the scattered light produced in the flow is

collected and sensed as a non-zero voltage output. The method of discrimination between the scattering signatures of the shock waves and the turbulent vortices is straightforward due to the two to three orders of magnitude difference. The scattered light from the shock waves is intense, causes near saturation of PMT and typically produces .5 to 5 volts 
peak to peak levels; while the scatted light from the turbulent fluctuations produce 5 to 50 millivolt levels. A voltage threshold level was established and PMT output above this level are considered due to the shocks. Moreover, the shocks are present at a few discrete regions, which can be approximately located from the schlieren photographs.

\section{RESULTS}

\section{A. Screech frequency, amplitude and mode:}

The screech tone frequencies and the relative amplitude levels for the circular, rectangular and the elliptic nozzles are shown in figs. 2, 3 and 4, respectively. Data are obtained using a fixed microphone placed slightly upstream of the nozzle exit and facing the downstream direction. The advantage of this position is that the acoustic spectra are little affected by the mixing noise components; keeping the screech footprints dominant. Only the fundamental tone frequencies are plotted in this figure. In addition to the harmonics, the sum and difference frequencies of the multiple fundamental tones are also present during mode switching. None of such frequencies are plotted in the above figures. It is now known that a screeching jet can support multiple fundamental tone simultaneously ${ }^{22}$. The amplitude levels change considerably depending on the microphone location. The purposes of the amplitude data are to show the relative strength of various modes, and the dependence on the $\mathrm{M}_{\mathrm{j}}$.

Figs. 2 and 4 show that the frequency 'staging' behavior is present in both circular and elliptic geometry nozzles. Fig. 3 shows that it is absent from the present rectangular geometry. In the past, many researchers have described the frequency staging of circular jets. An excellent description that matches almost every detail of fig. 2 is by Powell et $a l^{12}$. The only additional observation is the 'E' stage. Similar to Powell et al. ${ }^{12}$ 's description, data presented in ref 3 show that the modes A1 and A2 are axisymmetric, B and D are primarily flapping and the Mode C is helical. The mode shape of the 'E' stage is unknown. The jets from the elliptic nozzle also show two frequency stages at a relatively high Mach number range (fig. 4). The frequency stages are named as E1, E2 and E3. The frequency jump from the $\mathrm{E} 1$ to the $\mathrm{E} 2$ stage, at around $\mathrm{M}_{\mathrm{j}}=1.65$, was also observed by Zaman ${ }^{23}$; experiment on a similar nozzle by

Gutmark et $a l^{24}$., however, does not show any frequency staging. Zaman ${ }^{19}$ found both E1 and E2 modes to be flapping. The difference between the two modes, as well as the nature of the weak E3 mode are unknown. It is already mentioned that the rectangular nozzle used for the present experiment does not show frequency staging. However, such staging is reported for the smaller aspect ratio rectangular nozzles (ref 16).

A study of screech from the rectangular and elliptic jets is affected by an additional problem of axis-switching. The cross-sections of such jets may evolve in such a manner that, after a certain distance from the nozzle, the major and minor axes may interchange. There is evidence that screech may expedite the axis-switching; in addition, the corner vortices in a rectangular jet also play a role $\left(\operatorname{Zaman}^{19,23}\right)$. The 5:1 aspect ratio rectangular jet used in this experiment does not show axis switching $\left(\operatorname{Raman}^{18}\right)$; however, such a switch is present in the 3:1 aspect ratio elliptic jet (ref. 16).

\section{B. Standing wavelength and shock spacing}

The easiest means to identify the standing wave spacing is by measuring the root-mean-square (rms) pressure fluctuation along the shear layer boundary using a traversing microphone (ref 4). Such data, presented in fig. 5, show spatially periodic modulation. Data in fig. 5 were obtained from the circular jet, and the microphone was traversed parallel to the growing shear layer at an inclination angle of $5.7^{\circ}$ with respect to the jet centerline. To avoid breakage of the sensitive diaphragm, the microphone was always placed outside the turbulent, primary jet flow. It was closest to the jet at the nozzle lip where the radial distance from the centerline was 0.7 for $1.1 \leq \mathrm{M}_{\mathrm{j}} \leq 1.4$ and 0.9 for $\mathrm{M}_{\mathrm{j}}>1.4$.

The abscissa of fig. 5, representing the downstream distance from the nozzle exit, is normalized by the individual standing wave spacing measured from each data set. An interesting outcome of such a normalization is a near coincidence of the periodic pressure modulations measured from a wide range of jet operating conditions. This feature once again shows that the standing wavelength is an important length scale in a screeching jet.

The shock spacing in the shear layer of each jet $(\mathrm{r} / \mathrm{D}=0.45$ for a circular jet, $\mathrm{r} / \mathrm{h}=0.45$ for a rectangular jet and $\mathrm{r} /($ minor axis length $)=0.45$ for an elliptic jet) are measured using the optical, scattered light detection technique mentioned earlier. The laser beam is traversed from point to point and the rms voltage output from the photo-multiplier tube (PMT) is measured. Whenever a shock wave is encountered, strong laser light scattering produces a large peak in the PMT voltage ${ }^{3}$. It is also described in ref 3 that the shock waves in a screeching jet oscillate by a large amplitude. The shock positions mentioned in this paper may be interpreted as the center of oscillation. 
Fig. 6 shows a comparison between the average standing wavelengths and the average shock spacing. The spatial resolution in the standing wavelength data is limited by its relative size with respect to the microphone used for the measurement (a $3.2 \mathrm{~mm}$ diameter microphone was used for the circular jet data, and a $6.3 \mathrm{~mm}$ diameter one was used for the rectangular and elliptic jet). However, the average wavelength was obtained by averaging over at least four standing wavelengths, which significantly reduces the resolution error. It is estimated that the standing wavelength is measured within $\pm 3 \%$ accuracy. The accuracy of the shock spacing data is also limited by the spatial resolution of the laser beam traverse. The distance between the neighboring measurement points was $1.3 \mathrm{~mm}$ which, on an average, translates into an error of $\pm 1 \%$ in the average shock position data. Fig. 6 shows that the standing wave spacing is close to the shock spacing for all operating conditions. In general, one is either longer or shorter than the other. The trend switches with a change in the screech mode. For example, the standing wave spacing are greater than the average shock spacing for the flapping B mode in a circular jet (fig. 6a); however, as soon as the screech mode changes to the helical $\mathrm{C}$ mode the standing wave spacing becomes shorter than the shock spacing. With a further increase in the $\mathrm{M}_{\mathrm{j}}$ the flapping $\mathrm{D}$ mode kicks in and the standing wavelength once again becomes longer than the shock spacing. A similar trend is observed between the E1 to E2 mode switch in the elliptic jet (fig. 6c). There is no mode switching in the rectangular jet where a flapping mode persists throughout, and the standing wave spacing is always greater than the shock spacing.

An outstanding issue that naturally arises from the above observation is the reason for the difference between the two length scales: the standing wave spacing and the shock spacing. No satisfactory answer can be given at this point. It is known that the individual shock spacing changes progressively with downstream distance, and an average value, presented in fig. 6, is somewhat different from the individual numbers. In an effort to check whether the standing wave spacing corresponds to any individual shock spacing Table II is compiled from the detailed data set. Note that the average of the first 4 or 5 shock spacing is used as the average shock spacing. It is known that the first 4 or 5 shock cells are responsible for the screech generation ${ }^{4,5,6}$. Therefore, the spacing of the shocks beyond the 5 th one is not measured. Table II shows that the individual shock spacing vary by $10 \%$ to $15 \%$ from their mean value. For the rectangular and the elliptic jets the spacing between the shocks at first increases and then decreases. Nevertheless, no definite relation between the individual shock spacing and the standing wavelength can be found.

\section{Convective velocity of organized vortices:}

The primary difficulty in accurately measuring the convective velocity of the large organized vortices is the presence of a partially formed interference pattern between the acoustic and the hydrodynamic fluctuations even inside the jet shear layer (ref 4). A consequence of the interference, which once again appears as a standing wave, is to modulate the phase information (Wiegel and Wlezien ${ }^{25}$ ) from which the convective speed is calculated. Traditionally, convective velocity is calculated either from the spark schlieren photographs (Powell et al. ${ }^{12}$, Davies and Oldfield ${ }^{10}$, Krothapalli et $a l .{ }^{14}$ ) or by measuring the phase change along the axial direction ( $\mathrm{Hu}$ and McLaughlin ${ }^{9}$, Raman and Rice ${ }^{13}$ ). The wavelength $\left(\lambda_{h}\right)$ of the organized vortices is measured as the distance between two consecutive dark zones in the former, and as the distance over which the phase changes by $2 \pi$ in the latter. Finally, the convective velocity, $U_{c}$, is calculated from a knowledge of the screech frequency: $U_{c}=f_{s} \lambda_{h}$. The presence of the standing waves confuse the wavelength measurement. This is demonstrated in the following using the phase change method.

In the present experiment, the passage of the organized structures in the jet shear layer was detected by light scattering from a narrow laser beam passing perpendicular to the jet flow direction. The scattered light was sensed by a PMT as shown earlier in fig. 1. The laser assembly was moved from point to point in the shear layer and at each point the relative phase, $\phi(f, x)$ between the PMT signal, $R(x, t)$, and that of a fixed microphone $P(t)$ was determined by measuring the cross-spectral phase. The calculations are done in two stages. First, the cross-correlation function is determined as:

$$
\mathrm{C}_{\mathrm{RP}}(\tau, \mathrm{x})=\operatorname{Lim}_{\mathrm{T} \rightarrow \infty} \frac{1}{\mathrm{~T}} \int_{0}^{\mathrm{T}} \mathrm{R}(\mathrm{x}, \mathrm{t}) \mathrm{P}(\mathrm{t}+\tau) \mathrm{dt} .
$$

Second, the cross-spectral density function is calculated and written out in the complex form:

$$
\mathrm{S}_{\mathrm{RP}}(\mathrm{f}, \mathrm{x})=\int_{-\infty}^{\infty} \mathrm{C}_{\mathrm{RP}}(\tau, \mathrm{x}) \exp (-\mathrm{i} 2 \pi \mathrm{f} \tau) \mathrm{d} \tau=\left|\mathrm{S}_{\mathrm{RP}}(\mathrm{f}, \mathrm{x})\right| \exp (-\mathrm{i} \phi(\mathrm{f}, \mathrm{x})) .
$$


The polar angle at the right side provides the relative phase. The calculations were performed directly through a frequency analyzer (Spectral Dynamics) that provided an average phase over $128 \mathrm{~K}$ data points obtained over 6.4 seconds. Fig. 7 shows the measured axial phase variation in the shear layer $(r / D=0.48)$ of circular jets at the screech frequency, $\mathrm{f}=\mathrm{f}_{\mathrm{s}}$. (Note that data points are omitted at axial stations where the laser beam interacts with a shock. Since, a strong scattering by the shock waves completely overwhelms relatively weaker scattering by the organized structures, no phase measurements are possible at these stations). A closer look into the phase variation data shows an underlying sinuous modulation superimposed on the general linear increase. The modulations are more prominent at the higher Mach number jets. An examination of the earlier data by Hu and McLaughlin ${ }^{9}$ and Raman and Rice ${ }^{13}$ also shows the same sinuous modulations.

An explanation of the sinuous modulation lies in the interference caused by the presence of a standing wave inside the shear layer. If the PMT signal $\mathrm{R}(\mathrm{x}, \mathrm{t})$, sensed by the moving laser assembly is expressed as the sum of two waves as in the equation 1 , and stationary reference microphone signal is expressed as $\mathrm{P}(\mathrm{t})=\sin (\omega \mathrm{t})$. The resultant cross-correlation function becomes:

$$
\mathrm{C}_{\mathrm{RP}}(\tau, \mathrm{x})=\frac{\mathrm{A}}{2} \cos \left(\mathrm{k}_{\mathrm{s}} \mathrm{x}-\omega \tau\right)-\frac{\mathrm{B}}{2} \cos \left(\mathrm{k}_{\mathrm{h}} \mathrm{x}+\omega \tau\right) .
$$

The cross-spectral density function at the screech frequency is:

$$
\mathrm{S}_{\mathrm{RP}}(\mathrm{x})=\left(\frac{\mathrm{A}}{2} \cos \mathrm{k}_{\mathrm{s}} \mathrm{x}-\frac{\mathrm{B}}{2} \cos \mathrm{k}_{\mathrm{h}} \mathrm{x}\right)-\mathrm{i}\left(\frac{\mathrm{A}}{2} \sin \mathrm{k}_{\mathrm{s}} \mathrm{x}+\frac{\mathrm{B}}{2} \sin \mathrm{k}_{\mathrm{h}} \mathrm{x}\right) .
$$

Therefore, the cross-spectral phase is

$$
\phi(\mathrm{x})=\arctan \frac{\mathrm{A} \sin \left(\mathrm{k}_{\mathrm{S}} \mathrm{x}\right)+\mathrm{B} \sin \left(\mathrm{kh}_{\mathrm{h}} \mathrm{x}\right)}{\mathrm{B} \cos \left(\mathrm{k}_{\mathrm{h}} \mathrm{x}\right)-\mathrm{A} \cos \left(\mathrm{k}_{\mathrm{S}} \mathrm{x}\right)} .
$$

Clearly, the phase distribution is a function of the relative amplitude of the two waves. Fig. 8 shows the cross-spectral phase variation for the frequency and wave number combinations measured in the $\mathrm{M}_{\mathrm{j}}=1.42$ jet. Fig. 8(a) shows the phase variation if the acoustic contribution is absent, and fig. 8(b) shows the effect of a partial standing wave when the hydrodynamic contribution is three times the acoustic contribution, that is, $\mathrm{B}=3 \mathrm{~A}$. The experimentally obtained data for the same $\mathrm{M}_{\mathrm{j}}=1.42$ jet is shown in the preceding figure. The similarity between the data of fig. 7 and phase variation of fig. 8(b) supports the contention that the measured sinuous phase variation is an artifact of the interference effect.

In the traditional methods, the gradients of the straight lines fitted through the individual data sets of fig. 7 are used as measures of the average wavelength, which are then used to determine the average convective velocities. The troubling feature is that the phase change is hardly linear, especially at the higher Mach number conditions. Fitting a straight line through such a periodic function is subjective. It is also dependent on the fractional numbers of the standing wavelengths used for the fit. It is likely that such subjectiveness is a cause for the scatter in the experimentally observed convective velocity data. The physical manifestation of the sinuous phase variation is a nonuniform motion of the individual vortical structures seen in the schlieren photographs (ref 4). Therefore, the wavelength information obtained from such photographs are also affected by the partial standing wave formation.

The best method to circumvent this difficulty is to use the standing wavelength itself to calculate the convective velocity. A knowledge of the standing wavelength, $\mathrm{L}_{\mathrm{sw}}$, screech frequency, $\mathrm{f}_{\mathrm{s}}$, and the ambient sound speed, $\mathrm{c}$, are needed to determine the convective velocity from equation 3.

$$
\mathrm{U}_{\mathrm{c}}=\left(\frac{1}{\mathrm{f}_{\mathrm{S}} \mathrm{L}_{\mathrm{SW}}}-\frac{1}{\mathrm{c}}\right)^{-1}
$$

The simplest means to determine the standing wave spacing, without getting inside the high speed jet, is by measuring the pressure fluctuations very close to the jet boundary (discussed in the earlier section). Data from the fig. 6 are utilized to calculate the convective velocity variations shown in fig. 9 for all three nozzle geometry. Since the standing wavelengths can be measured very accurately, the convective velocity measurements are fairly accurate. It has been mentioned that the standing wavelength is measured with $\pm 3 \%$ accuracy; this translates into a maximum $\pm 5 \%$ error in the convective velocity data.

Following a standard practice, the convective velocity data of fig. 9 are nondimensionalized by the ideally expanded jet velocity $U_{j}$. The latter is an hypothetical velocity from a perfectly expanded convergent-divergent nozzle operating at the same pressure ratio in which the underexpanded jet is operating. An interesting result that comes out of 
the correctly measured convective velocity data is the jump associated with each frequency staging. For the circular jet of fig. $9(\mathrm{a}), \mathrm{U}_{\mathrm{c}} / \mathrm{U}_{\mathrm{j}}$ jumps from an average of 0.67 in the axisymmetric $\mathrm{A} 1$ and $\mathrm{A} 2$ modes to 0.58 in the flapping B mode and then back to 0.66 for the helical $C$ mode (Table I). Similarly, for the elliptic jet, $U_{c} / U_{j}$ changes from an average 0.6 in E1 mode to 0.65 in the E2 mode. Such a staging phenomenon was also observed by Powell et al. ${ }^{12}$ from an examination of the schlieren photographs; however, the current data is believed to be more accurate. Linear stability analysis of supersonic fully expanded jets $\left(\right.$ Morris $^{26}$ ) demonstrates differences in the convective velocities for the different modes. However, the numbers mentioned above could not be compared with any computational data, since, a stability analysis of a shock containing jet is yet to be done. Another trend apparent from fig. 9 is that the convective velocity starts to increase at a higher $\mathrm{M}_{\mathrm{j}}$ when screech becomes weaker. The convective velocity of the $\mathrm{M}_{\mathrm{j}}=1.4$ jet from a rectangular nozzle, mentioned in the introduction, is found to be $0.59 \mathrm{U}_{\mathrm{j}}$.

\section{SUMMARY AND CONCLUDING REMARKS}

Screech characteristics of unheated, supersonic, underexpanded jets issuing from a circular, a 5:1 aspect ratio rectangular and, a 3:1 aspect ratio elliptic nozzle are investigated experimentally over the nominal range, $1.1 \leq \mathrm{M}_{\mathrm{j}} \leq$ 1.9. The shock spacing in the jet shear layer is measured using the light scattering properties from a narrow laser beam. The shock spacing is compared with the wavelength of the standing wave system that wraps around the jet. The standing wavelength is obtained from a measurement of the sound pressure level variation just outside the jet shear layer, using a traversing microphone. Interestingly, it is found that the two length scales (shock spacing, L, and standing wavelength, $\mathrm{L}_{\mathrm{sw}}$ ) are close, albeit different, for all the nozzle geometry and the jet operating conditions. For a given nozzle geometry, as $\mathrm{M}_{\mathrm{j}}$ is increased (by increasing the plenum to the ambient pressure ratio) the shock spacing increases, so does the standing wavelength. In the rectangular jet, where no frequency staging exists, $\mathrm{L}_{\mathrm{sw}}$ is longer than L. For circular and elliptic geometry jets the scenario depends on the screech mode shape. For the helical $\mathrm{C}$ mode of a circular jet and the E2 mode of a elliptic jet $\mathrm{L}_{\mathrm{sw}}<\mathrm{L}$, while for the flapping B and D modes of circular jet and the flapping E1 mode of the elliptic jet $\mathrm{L}_{\mathrm{sw}}>\mathrm{L}$. While no explanation can be provided for the observed trend, the outcome of the trend may affect the screech generation process. It is possible that the difference between the standing wavelength and the shock spacing dictates the efficiency of the feedback loop in generating sound.

A second contribution of this paper is to present correctly measured convective velocity of the organized vortices. It is shown that the presence of the acoustic-hydrodynamic interference even inside the jet shear layer renders inaccuracy in the traditional techniques. A new substitute, based on a measurement of the standing wavelength, provides more accurate data. The convective velocities measured by this technique show a staging pattern coincidental with the frequency staging. Another trend apparent from the data is that the convective velocity starts to increase at higher $\mathrm{M}_{\mathrm{j}}$ when screech becomes weaker.

\section{References}

${ }^{1}$ Hay, J. A. \& Rose, E. G. 1970 In flight shock cell noise. J. Sound \& Vib., vol. 11, 411-420.

${ }^{2}$ Cain, A. B., Bower, W. W., Walker, S. H. \& Lockwood, M. K. 1995 Modeling supersonic jet screech Part 1: vortical instability wave modeling. AIAA paper 95-0506.

${ }^{3}$ Panda, J. June 1995a Measurement of shock oscillation in underexpanded supersonic jets. AIAA paper 95-2145.

${ }^{4}$ Panda, J. 1996 An Experimental Investigation of Screech Noise Generation. AIAA paper 96-1718, presented at the 2nd AIAA/CEAS Aeroacoustics Conf.

${ }^{5}$ Powell, A. 1953b On The mechanism of choked jet noise. Proc. phys. Soc. (London), Vol. 66, pt. 12, No. 408B, 1039-1056.

${ }^{6}$ Powell, A. 1953a On the noise emanating from a two-dimensional jet above the critical pressure, The Aeronautical Quarterly, Vol. IV, 103-122.

${ }^{7}$ Tam, C. K. W. 1988 The shock-cell structures and screech tone frequencies of rectangular and non-axisymmetric supersonic jets. J. Sound \& Vib., vol. 121, no. 1, 135-147.

${ }^{8}$ Morris, P. J., Bhat, T. R. S. and Chen, G. 1989 A linear shock cell model for jets of arbitrary exit geometry. J. Sound \& Vib., vol. 132, no. 2, 199-211. 
${ }^{9}$ Hu, T. F. \& McLaughlin, D. K. 1990 Flow and acoustic properties of low mach number underexpanded supersonic jets. J. Sound Vib., Vol. 141, 485-505.

${ }^{10}$ Davies, M. G. \& Oldfield, D. E. S. 1962 Tones from a choked axisymmetric jet. Acustica, 12(4), 257-277.

${ }^{11}$ Tam, C. K. W., Seiner, J. M. \& Yu, J. C. 1986 Proposed relationship between broadband shock associated noise and screech tone. J. Sound Vib., Vol. 110, no. 2, 309-321.

${ }^{12}$ Powell, A., Umeda, Y. and Ishii R. 1992 Observation of oscillation modes of choked circular jets. J. Acoust. Soc. Am. Vol. 92, no. 5, 2823-2836.

${ }^{13}$ Raman, G. \& Rice, E. J. Dec. 1994 Instability modes excited by natural screech tones in a supersonic rectangular jet. Physics of Fluids, Vol. 6, no. 2, 3999-4008.

${ }^{14}$ Krothapalli, A., Hsia, Y., Baganoff, D. and Karamcheti, K. 1986 The role of screech tones in mixing of an underexpanded rectangular jet. J. Sound \& Vib., vol. 106, no. 9, 119-143.

${ }^{15}$ Raman, G., Panda, J. and Zaman, K. 1997 Feedback and receptivity during jet screech; influence of an upstream reflector. AIAA paper no. 97-0144.

${ }^{16}$ Nagel, R. T., Denham, J. W. and Papathanasiou, A. G. 1983 Supersonic jet screech tone cancellation. AIAA J., vol. 21, no. 11, 1541-1545.

${ }^{17}$ Fisher, M. J., and Morfey, C. L. Dec. 1976 Jet noise, in AGARD Lecture Series No. 80, Aerodynamic Noise.

${ }^{18}$ Raman, G. 1996 Cessation of Screech in Underexpanded Jets. AIAA paper 96-1719, presented at the 2nd AIAA/CEAS Aeroacoustics Conf.

${ }^{19}$ Zaman, K. B. M. Q. 1994 Effect of 'delta tabs' on mixing and axis switching in jets from asymmetric nozzles. AIAA paper no. 94-0186.

${ }^{20}$ Panda, J. 1995 Wide angle light scattering in shock-laser interaction. AIAA J. 33 (12), 2429-2431.

${ }^{21}$ Panda, J. and Adamovsky, G. 1995 Laser light scattering by shock waves. Physics of Fluids 7 (9), 2271-2279.

${ }^{22}$ Walker, S. H., Gordeyev, S. \& Thomas, F. O. 1997 Wavelet transformation analysis applied to unsteady aspect of supersonic jet screech resonance. Expts. in Fluids, 22(6).

${ }^{23}$ Zaman, K. B. M. Q. 1996 Axis switching and spreading of an asymmetric jet: the role of coherent structure dynamics. J. Fluid Mech. 316, 1-27.

${ }^{24}$ Gutmark, E., Schadow, K. C., Wilson, K. J. and Bicker, C. J. 1988 Near-field pressure radiation and flow characteristics in low supersonic circular and elliptic jets. Physics of Fluids, vol. 31, no. 9., 2524-2532.

${ }^{25}$ Wiegel, M. \& Wlezien, R. W. 1993 Acoustic receptivity of laminar boundary layers over wavy walls. AIAA paper no. 93-3280.

${ }^{26}$ Morris, P. J. 1977 Flow characteristics of the large scale wave-like structure of a supersonic round jet. J. Sound Vib., 53(2), 223-244. 
Table I. Convective velocity of organized vortices in screeching jets

\begin{tabular}{|c|c|c|c|}
\hline Nozzle type & $\mathrm{M}_{\mathrm{j}}$ & $\mathrm{U}_{\mathrm{c}} / \mathrm{U}_{\mathrm{j}}$ & Source / Comments \\
\hline Circular & 1.4 & 0.55 & Hu \& McLaughlin', helical screech mode \\
\hline \multirow[t]{11}{*}{ choked } & 2.1 & 0.66 & same \\
\hline & large range & 0.65 & Davies \& Oldfield $^{10}$ \\
\hline & All $\mathrm{M}_{\mathrm{j}}$ & 0.7 & Tam, Seiner \& $\mathrm{Yu}^{11}$ (screech model) \\
\hline & A mode & $0.64 *$ & Powell, Umeda \& Ishii ${ }^{12}$; Average value \\
\hline & B mode & $0.68^{*}$ & same \\
\hline & $\mathrm{C}$ mode & $0.8^{*}$ & same \\
\hline & D mode & $0.75^{*}$ & same \\
\hline & A mode & 0.67 & PRESENT DATA \\
\hline & B mode & 0.58 & same \\
\hline & C mode & 0.66 & same \\
\hline & D mode & 0.69 & same \\
\hline \multirow{7}{*}{$\begin{array}{l}\text { Rectangular } \\
\text { choked }\end{array}$} & 1.43 & 0.44 & Powell $^{6}$, rectangular nozzle from a circular plenum \\
\hline & 1.44 & 0.604 & Powell ${ }^{6}$, rectangular nozzle from a square plenum \\
\hline & 1.44 & 0.54 & Raman \& Rice ${ }^{13}$ \\
\hline & All $\mathrm{M}_{\mathrm{j}}$ & 0.7 & $\operatorname{Tam}^{7}$ (screech model) \\
\hline & 1.47 & 0.5 & Krothapalli et al. ${ }^{14}$ \\
\hline & 1.41 & 0.59 & PRESENT DATA \\
\hline & 1.8 & 0.72 & same \\
\hline
\end{tabular}

*Note added after publication: these are $\mathrm{U}_{\mathrm{c}} / \mathrm{c}$ values, $\mathrm{c}$ : ambient sound speed

Table II. Shock spacing and standing wavelengths in screeching jets

\begin{tabular}{|c|c|c|c|c|c|c|c|c|}
\hline \multirow{2}{*}{$\begin{array}{l}\text { Nozzle } \\
\text { type }\end{array}$} & \multirow[t]{2}{*}{$\mathrm{M}_{\mathrm{j}}$} & \multirow{2}{*}{$\begin{array}{l}\text { Average standing } \\
\text { wavespacing }\end{array}$} & \multirow{2}{*}{$\begin{array}{l}\text { Average shock } \\
\text { spacing }\end{array}$} & \multicolumn{5}{|c|}{ Spacing of individual shock } \\
\hline & & & & Nozz-1st & 1 st-2nd & 2nd-3rd & 3rd-4th & 4th-5th \\
\hline \multirow[t]{2}{*}{ Circular $^{* *}$} & 1.19 & 0.672 & 0.77 & .77 & .78 & 0.82 & 0.7 & .77 \\
\hline & 1.42 & 1.087 & 1.24 & 1.3 & 1.3 & 1.3 & 1.2 & 1.1 \\
\hline \multirow[t]{3}{*}{ Rectang ${ }^{\S}$. } & 1.32 & 1.85 & 1.74 & 1.7 & 1.72 & 1.72 & 1.89 & 1.67 \\
\hline & 1.6 & 3.33 & 3.04 & 2.77 & 3.2 & 3.06 & 3.15 & 3.24 \\
\hline & 1.8 & 5.07 & 4.41 & 4.07 & 4.26 & 5. & 4.54 & 4.17 \\
\hline \multirow[t]{2}{*}{ Elliptic ${ }^{\pi}$} & 1.27 & 20.3 & 20.3 & 17.8 & 19.7 & 22.2 & 21.6 & \\
\hline & 1.75 & 24.1 & 25.9 & 24.1 & 25.4 & 26.7 & 27.9 & 25.4 \\
\hline
\end{tabular}

${ }^{* *}$ All quantities are nondimensionalized by the nozzle diameter (D). ${ }^{\S}$ All quantities are nondimensionalized by the small dimension of nozzle (h). "No nondimensionalization is used; all dimensions are in $\mathrm{mm}$. 
Table II. Shock spacings and standing wavelengths in screeching jets

\begin{tabular}{|c|c|c|c|c|c|c|c|c|}
\hline \multirow{2}{*}{$\begin{array}{c}\text { Nozzle } \\
\text { type }\end{array}$} & \multirow[t]{2}{*}{$\overline{M_{1}}$} & \multirow{2}{*}{$\begin{array}{c}\text { Average } \\
\text { standing } \\
\text { wave } \\
\text { spacing }\end{array}$} & \multirow{2}{*}{$\begin{array}{l}\text { Average } \\
\text { shock } \\
\text { spacing }\end{array}$} & \multicolumn{5}{|c|}{ Spacing of individual shock } \\
\hline & & & & Nozz-1st & 1 st-2nd & 2nd-3rd & 3 rd-4th & 4th-5th \\
\hline Circular"** & $\begin{array}{l}1.19 \\
1.42\end{array}$ & $\begin{array}{l}0.672 \\
1.087\end{array}$ & $\begin{array}{l}0.77 \\
1.24\end{array}$ & $\begin{array}{l}.77 \\
13 \\
\end{array}$ & $\begin{array}{l}.78 \\
13\end{array}$ & $\begin{array}{c}0.82 \\
1.3\end{array}$ & $\begin{array}{l}0.7 \\
12\end{array}$ & $\begin{array}{l}.77 \\
1.1\end{array}$ \\
\hline Rectang. & $\begin{array}{l}1.32 \\
1.6 \\
1.8\end{array}$ & $\begin{array}{l}1.85 \\
3.33 \\
5.07\end{array}$ & $\begin{array}{l}1.74 \\
3.04 \\
4.41\end{array}$ & $\begin{array}{l}1.7 \\
277 \\
4.07\end{array}$ & $\begin{array}{c}1.72 \\
32 \\
4.26\end{array}$ & $\begin{array}{c}1.72 \\
3.06 \\
5.0\end{array}$ & $\begin{array}{l}1.89 \\
3.15 \\
4.54\end{array}$ & $\begin{array}{l}1.67 \\
3.24 \\
4.17\end{array}$ \\
\hline Elliptic ${ }^{1}$ & $\begin{array}{l}1.27 \\
1.75\end{array}$ & $\begin{array}{l}20.3 \\
24.1\end{array}$ & $\begin{array}{l}20.3 \\
25.9\end{array}$ & $\begin{array}{l}17.8 \\
24.1\end{array}$ & $\begin{array}{l}19.7 \\
25.4\end{array}$ & $\begin{array}{l}222 \\
26.7\end{array}$ & $\begin{array}{l}21.6 \\
27.9\end{array}$ & 24.4 \\
\hline
\end{tabular}

**All quantities are nondimensionalized by the nozzle diameter (D).

'All quantities are nondimensionalized by the small dimension of nozzle (h).

${ }^{\mathbf{T}}$ No nondimensionalization is used; all dimensions are in $\mathrm{mm}$.

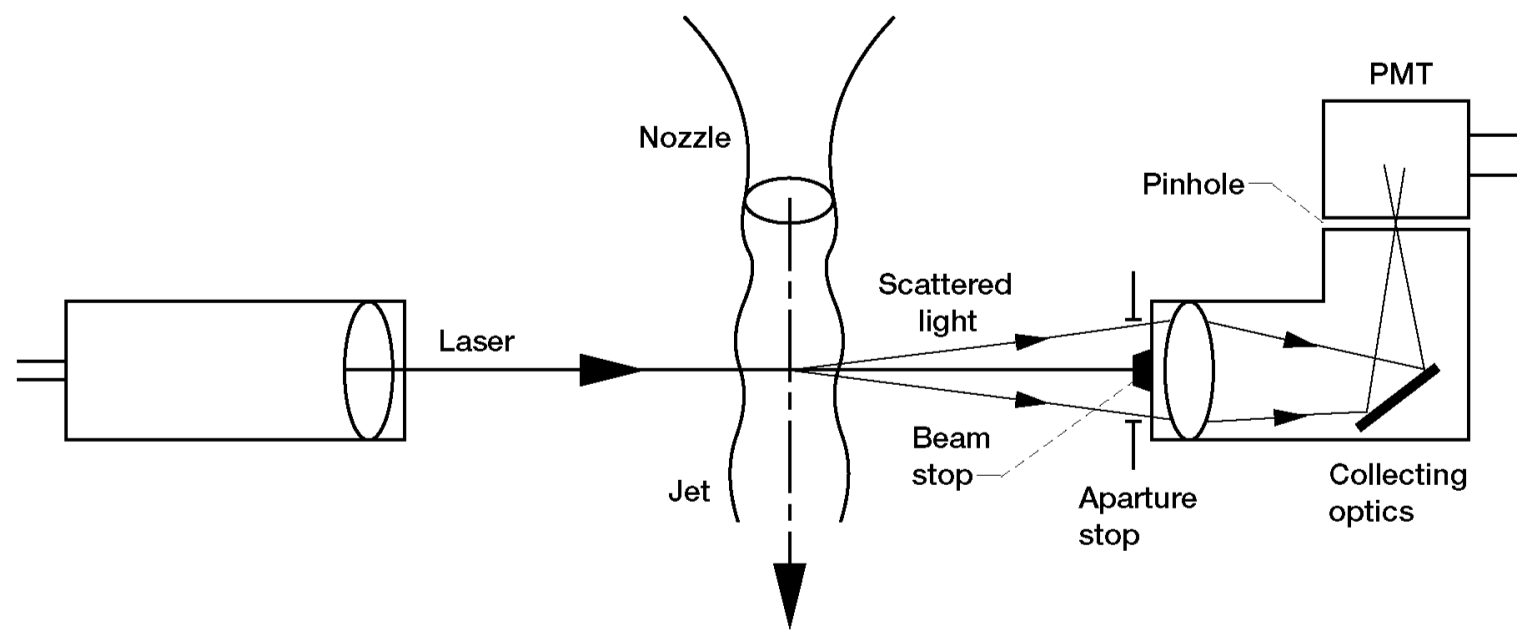

Figure 1.-Schematic of optical detection system.
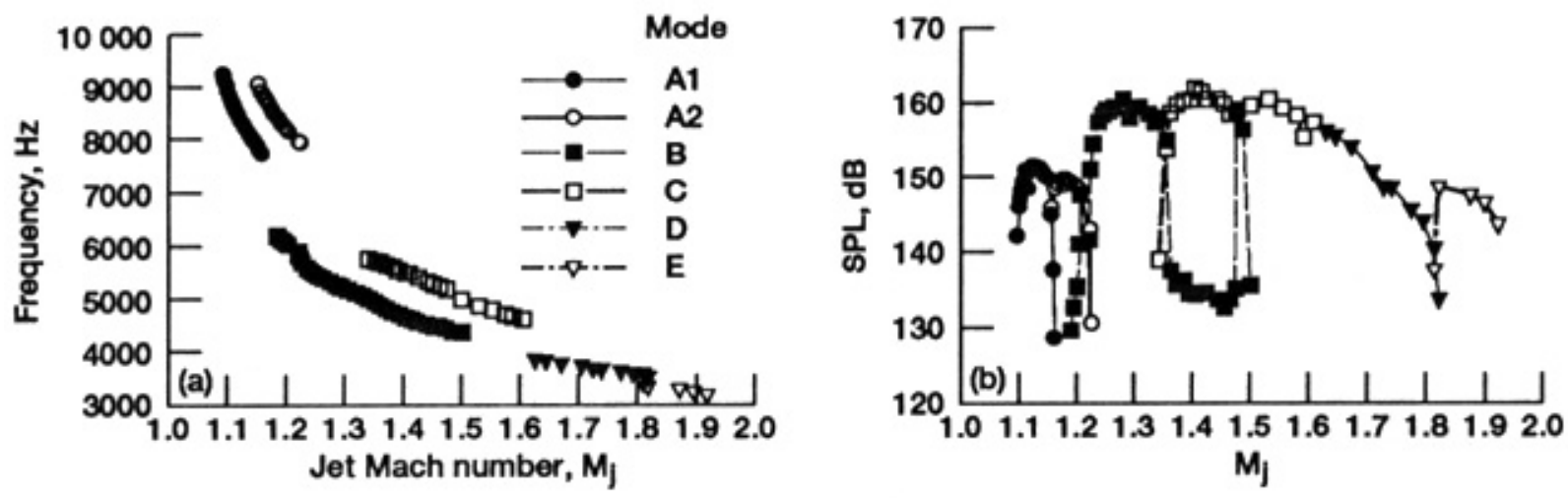

Figure 2.- (a) Screech frequency and (b) relative amplitude levels from an axisymmetric convergent nozzle. Legend shows screech modes. 

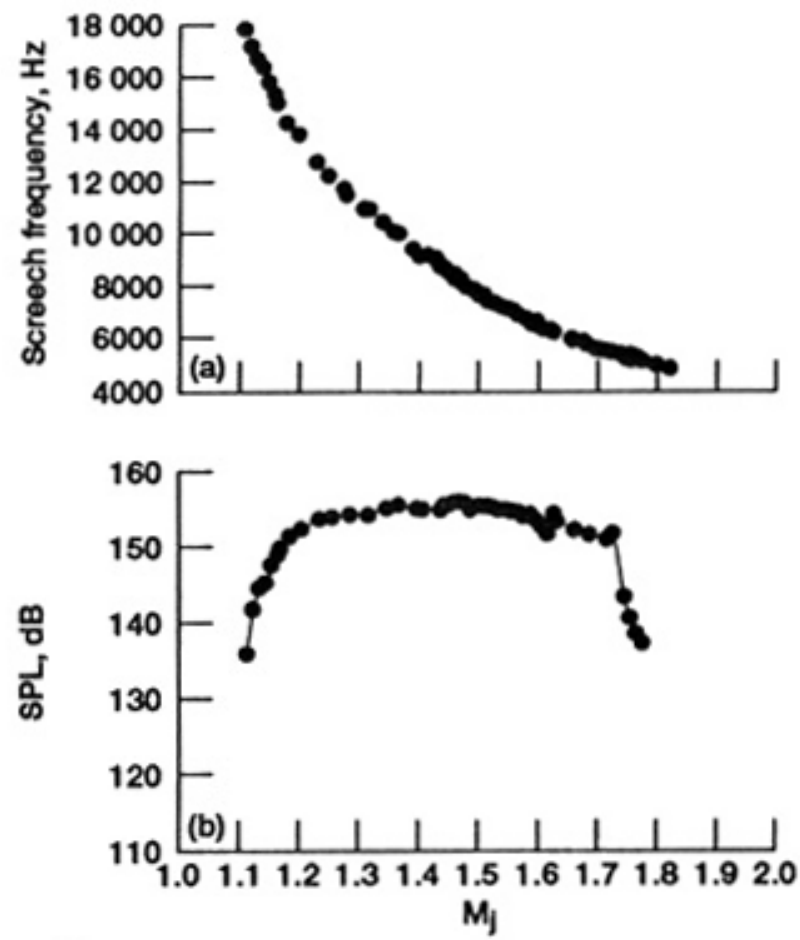

Figure 3.- (a) Screech frequency and (b) relative amplitude levels from a 5:1 aspect ratio rectangular nozzle.
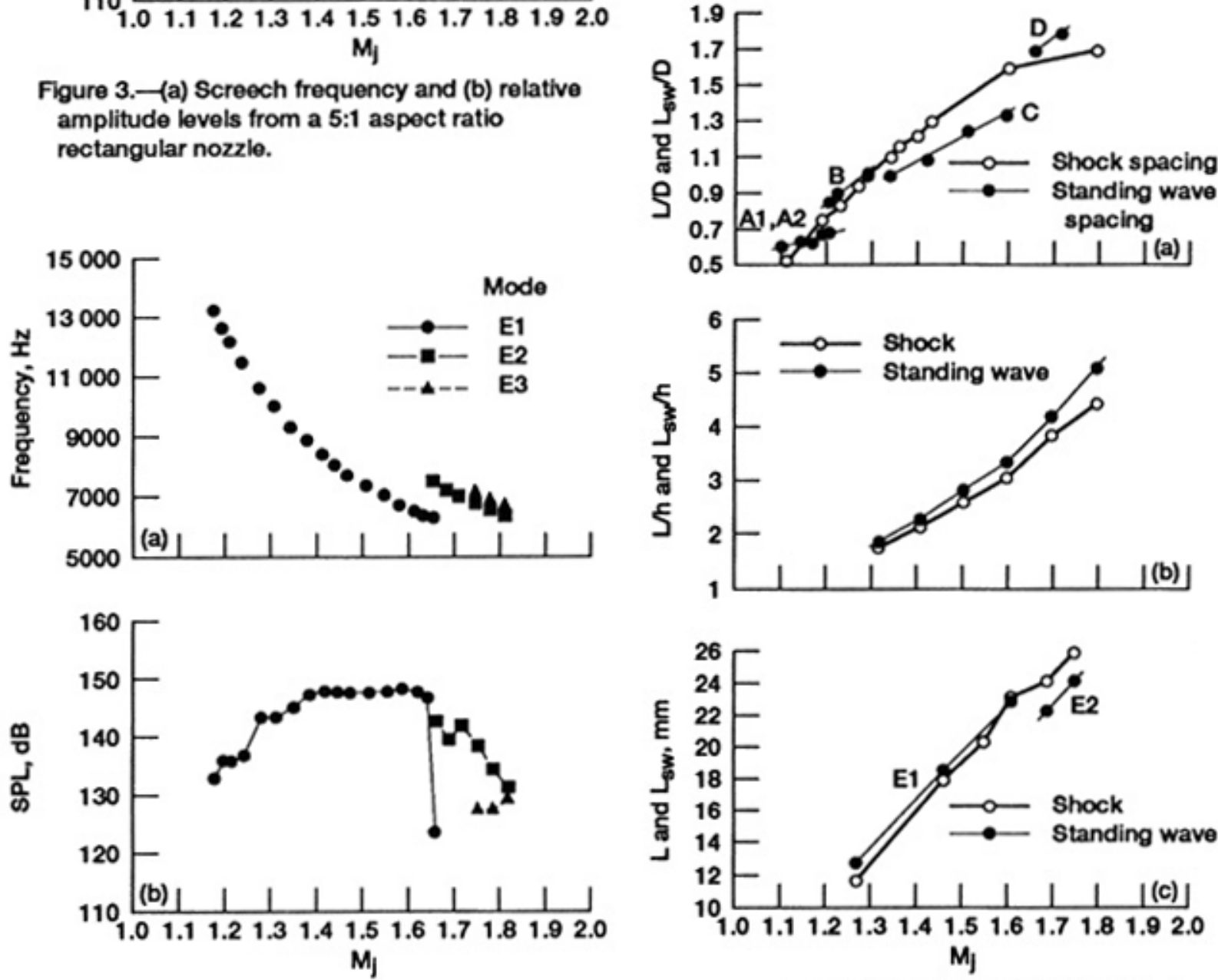

Figure 4.-(a) Screech frequency and (b) amplitude levels from a 3:1 major to minor axes ratio elliptic nozzle. Legend shows various screech modes.

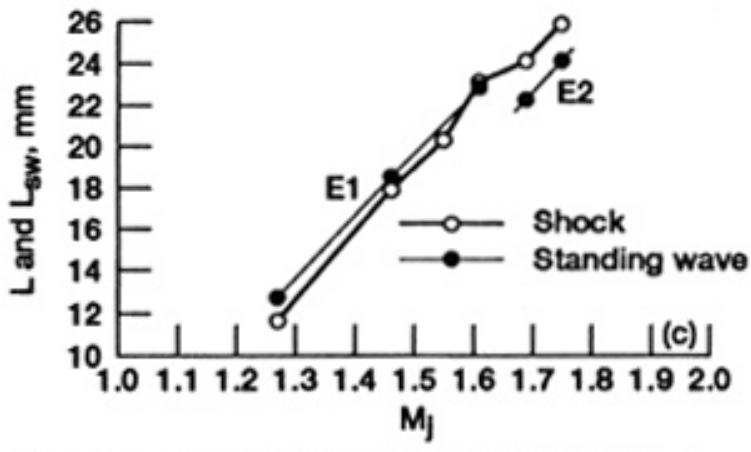

Figure 6.-Comparison between average shock spacing and average standing wave spacing for jets; (a) Circular. (b) Rectangular. (c) Elliptic. 


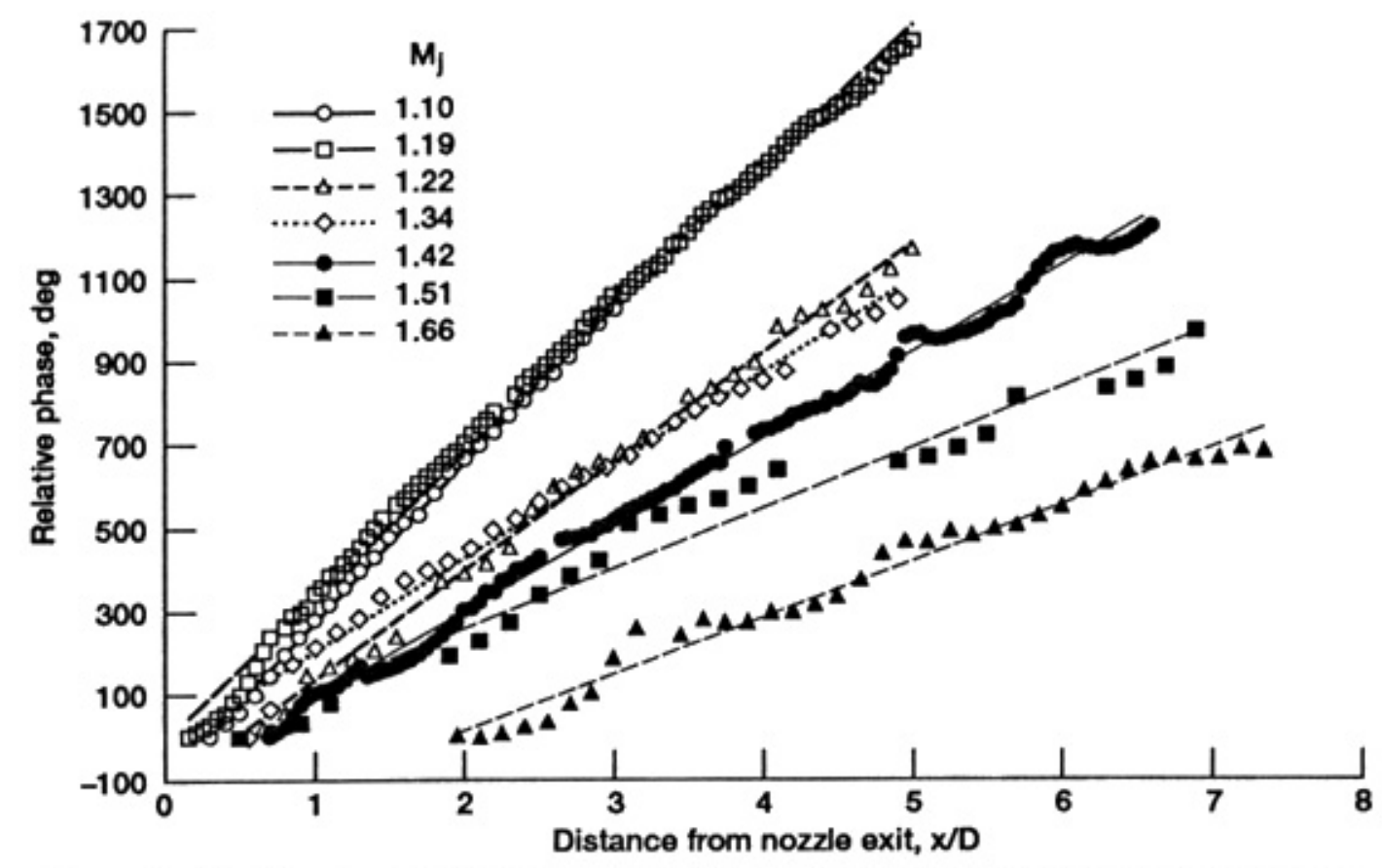

Figure 7.-Relative phase variations from organized vortices in shear layer of circular jets at indicated Mach number conditions. Straight lines are least square fits.
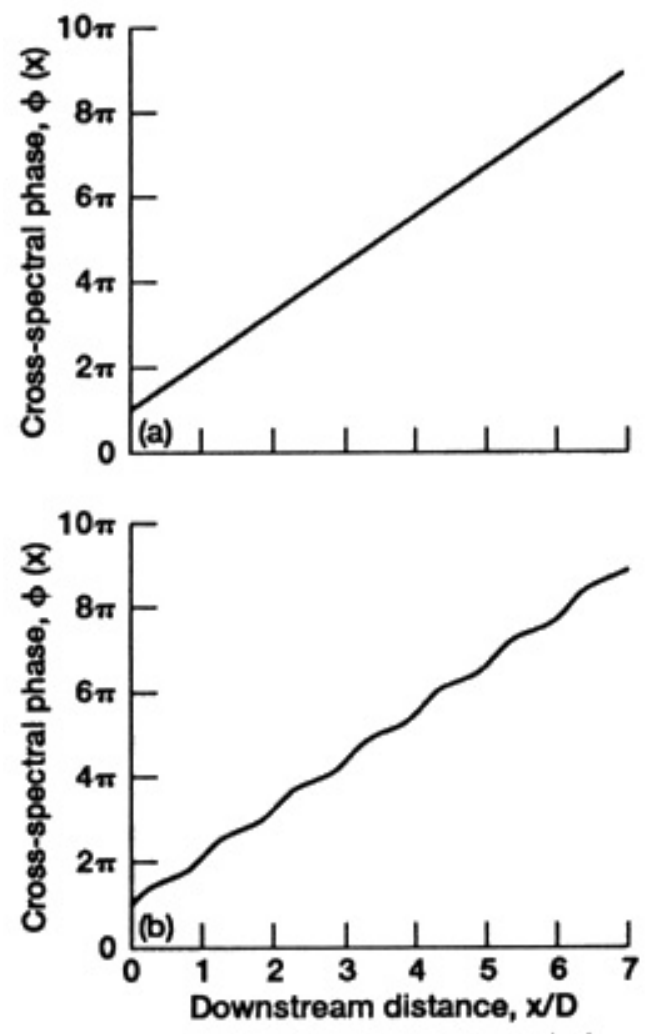

Figure 8.-Cross-spectral phase variation.

(a) For single downstream propagating wave. (b) For two oppositely moving waves forming a partial standing wave.
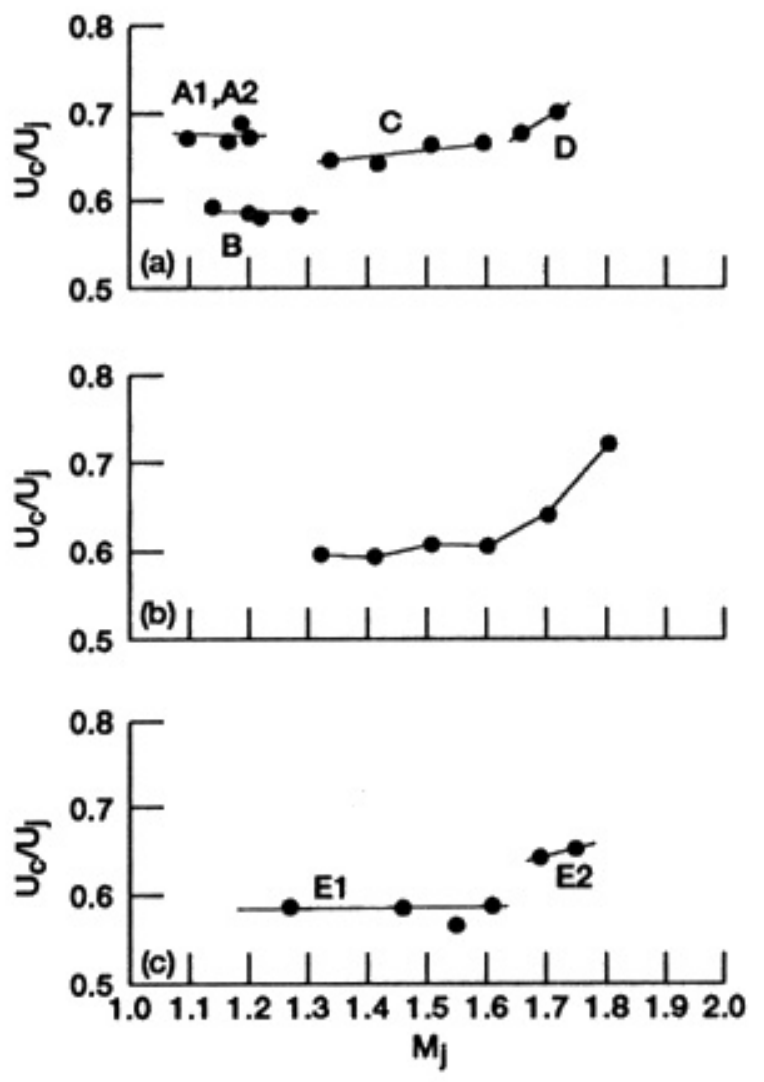

Figure 9.-Convective velocity variation in

(a) Circular, (b) Rectangular, (c) Eliptic jets. 
Public reporting burden for this collection of information is estimated to average 1 hour per response, including the time for reviewing instructions, searching existing data sources, gathering and maintaining the data needed, and completing and reviewing the collection of information. Send comments regarding this burden estimate or any other aspect of this collection of information, including suggestions for reducing this burden, to Washington Headquarters Services, Directorate for Information Operations and Reports, 1215 Jefferson Davis Highway, Suite 1204, Arlington, VA 22202-4302, and to the Office of Management and Budget, Paperwork Reduction Project (0704-0188), Washington, DC 20503.

\begin{tabular}{|l|c|c|}
\hline 1. AGENCY USE ONLY (Leave blank) & $\begin{array}{c}\text { 2. REPORT DATE } \\
\text { May } 2004\end{array}$ & $\begin{array}{r}\text { 3. REPORT TYPE AND DATES COVERED } \\
\text { Technical Memorandum }\end{array}$ \\
\hline
\end{tabular}

4. TITLE AND SUBTITLE 5. FUNDING NUMBERS

Underexpanded Screeching Jets From Circular, Rectangular, and Elliptic Nozzles

6. AUTHOR(S)

WBS-22-714-08-14

J. Panda, G. Raman, and K.B.M.Q. Zaman

7. PERFORMING ORGANIZATION NAME(S) AND ADDRESS(ES)

8. PERFORMING ORGANIZATION REPORT NUMBER

National Aeronautics and Space Administration

John H. Glenn Research Center at Lewis Field

Cleveland, Ohio 44135-3191

E-14019

\section{SPONSORING/MONITORING AGENCY NAME(S) AND ADDRESS(ES)}

National Aeronautics and Space Administration

Washington, DC 20546-0001

10. SPONSORING/MONITORING AGENCY REPORT NUMBER

NASA TM-2004-212481

AIAA-97-1623

\section{SUPPLEMENTARY NOTES}

Prepared for the Third Aeroacoustics Conference cosponsored by the American Institute of Aeronautics and Astronautics and the Confederation of European Aerospace Societies, Atlanta, Georgia, May 12-14, 1997. J. Panda, Modern Technologies Corporation, Middleburg Heights, Ohio 44130 (presently with Ohio Aerospace Institute); G. Raman, NYMA, Inc., Brook Park, Ohio 44142 (presently with Illinois Institute of Technology); K.B.M.Q. Zaman, NASA Glenn Research Center. Responsible person, J. Panda, organization code 5940, 216-433-8891.

\begin{tabular}{l|l} 
12a. DISTRIBUTION/AVAILABILITY STATEMENT & 12b. DISTRIBUTION CODE
\end{tabular}

Unclassified - Unlimited

Subject Category: 45

Distribution: Nonstandard

Available electronically at http://gltrs.grc.nasa.gov

This publication is available from the NASA Center for AeroSpace Information, 301-621-0390.

\section{ABSTRACT (Maximum 200 words)}

The screech frequency and amplitude, the shock spacing, the hydrodynamic-acoustic standing wave spacing, and the convective velocity of large organized structures are measured in the nominal Mach number range of $1.1 \leq \mathrm{M}_{\mathrm{j}} \leq 1.9$ for supersonic, underexpanded jets exhausting from a circular, a rectangular and an elliptic nozzle. This provides a carefully measured data set useful in comparing the importance of various physical parameters in the screech generation process. The hydrodynamic-acoustic standing wave is formed between the potential pressure field of large turbulent structures and the acoustic pressure field of the screech sound. It has been demonstrated earlier that in the currently available screech frequency prediction models replacement of the shock spacing by the standing wave spacing provides an exact expression. In view of this newly found evidence, a comparison is made between the average standing wavelength and the average shock spacing. It is found that there exists a small, yet important, difference, which is dependent on the azimuthal screech mode. For example, in the flapping modes of circular, rectangular, and elliptic jets, the standing wavelength is slightly longer than the shock spacing, while for the helical screech mode in a circular jet the opposite is true. This difference accounts for the departure of the existing models from predicting the exact screech frequency. Another important parameter, necessary in screech prediction, is the convective velocity of the large organized structures. It is demonstrated that the presence of the hydrodynamicacoustic standing wave, even inside the jet shear layer, becomes a significant source of error in the convective velocity data obtained using the conventional methods. However, a new relationship, using the standing wavelength and screech frequency is shown to provide more accurate results.

\section{SUBJECT TERMS}

Jet aircraft noise 15. NUMBER OF PAGES 18

\begin{tabular}{|c|c|c|}
\hline $\begin{array}{c}\text { 17. SECURITY CLASSIFICATION } \\
\text { OF REPORT } \\
\text { Unclassified }\end{array}$ & $\begin{array}{c}\text { 18. SECURITY CLASSIFICATION } \\
\text { OF THIS PAGE } \\
\text { Unclassified }\end{array}$ & $\begin{array}{c}\text { 19. SECURITY CLASSIFICATION } \\
\text { OF ABSTRACT } \\
\text { Unclassified }\end{array}$ \\
\hline
\end{tabular}



